\title{
Swyer's syndrome: a rare cause of primary amenorrhoea
}

\author{
Kusuma Naik M.V**, Nusrat A.H., Krishna L, Avinash Patil, Pallavi
}

\begin{abstract}
Department of Obstetrics \& Gynecology, PES Institute of Medical Sciences \& Research, Kuppam, Andhra Pradesh,
\end{abstract} India

Received: 27 September 2013

Accepted: 8 October 2013

\section{*Correspondence:}

Dr. Kusuma Naik M.V.,

E-mail: kusumamv@yahoo.co.in

(C) 2013 Kusuma Naik MV et al. This is an open-access article distributed under the terms of the Creative Commons Attribution Non-Commercial License, which permits unrestricted non-commercial use, distribution, and reproduction in any medium, provided the original work is properly cited.

\begin{abstract}
This is a rare case of pure gonadal dysgenesis, the exact incidence of the condition is unknown but can be estimated at 1:80 000 births. The patient presented with primary amenorrhoea , after complete evaluation it was diagnosed as Swyer's syndrome, which is 46,XY complete gonadal dysgenesis (46,XY CGD) characterized by a 46,XY karyotype, normal female external genitalia, completely undeveloped ("streak") gonads, no sperm production, and presence of normal müllerian structures.
\end{abstract}

Keywords: Swyer's syndrome, Primary amenorrhoea, Karyotyping

\section{INTRODUCTION}

Swyer's syndrome was first described by Gim Swyer in 1955. Affected individuals have an XY karyotype but the external and internal genitalia is of the female type. The gonads are usually replaced by fibrous streaks. Patients usually present in adolescence with primary amenorrhoea and lack of secondary sexual characteristics. The exact incidence of the condition is unknown but can be estimated at 1:80 000 births. $^{5}$ It is an extremely rare condition.

\section{CASE REPORT}

A 16 year old girl was brought to the out patient department by her parents, with complaints of primary amenorrhoea.

H/o hoarseness of voice since the age of $10 \mathrm{yrs}$. She did not give any history of cyclical abdominal pain, hormonal intake, radiation exposure, chemotherapy or any central nervous symptoms such as headache or visual disturbances. She gave no history of significant trauma or of having undergone any surgical procedure. There was no history of childhood tuberculosis nor was there a history of Koch's in the family.
She was the second issue of a non consanguineous marriage and mother's age at the time of delivery was 20 years. She has one elder $\&$ one younger brother who are 18 \& 11years respectively.

On general examination 16 yrs girl alert conscious thin tall built, well nourished $\mathrm{Ht}-160 \mathrm{~cm}$, Wt $-50 \mathrm{~kg} \mathrm{BMI}-$ 19.5, Arm span - $150 \mathrm{~cm}$, no turners stigmata, no hirsutism, acne, thyroid normal, Breast tanners stage II, sparse axillary hair, normal spine \& carrying angle

BP - 116/70 mm Hg, PR - 80 min, CVS - S1S2, Resp NVBS,

Per abdomen - soft, non tender, hernia orifices normal, no organomegaly, no free fluid

Examination of secondary sexual characteristics revealed that the breast was small and poorly developed with hypopigmented areola (Tanner's Stage II). Pubic hair was absent though the axillary hair was sparse. Examination of the external genitalia revealed that they were of female type and there was no evidence of clitoromegaly.

Pelvic ultrasound showed - Right kidney $-11 \mathrm{X} 1.8 \mathrm{~cm}$, left Kidney - 11 X1.8 cm. 
Uterus - very small amount of tissue is seen interposing between bladder $\&$ rectum

Rt ovary - 2.6 X 1.6 Cm, left ovary $-1.7 \mathrm{~cm} \mathrm{X} 1.3 \mathrm{~cm}$

Impression - Infantile uterus

Examination under anaesthesia

Local examination -

- Female external genitalia present

- Pubic hair absent

- Mons pubis pad of fat reduced

- Clitoris normal

- Labia majora \& minora normal for age

- No mass palpable in inguinal / labial area

- Hymen absent

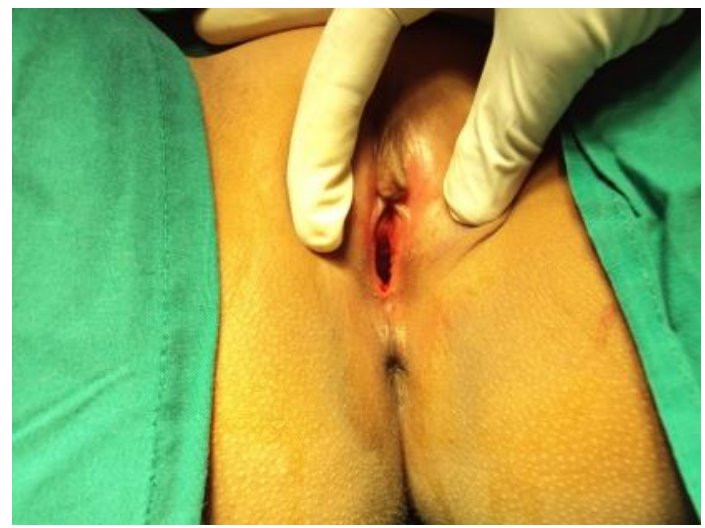

Figure 1: Normal female external genitalia, absent hymen.

Per Speculum

- Vagina dry \& bleeds on touch

- Hypoplastic cervix

- Pinpoint external os

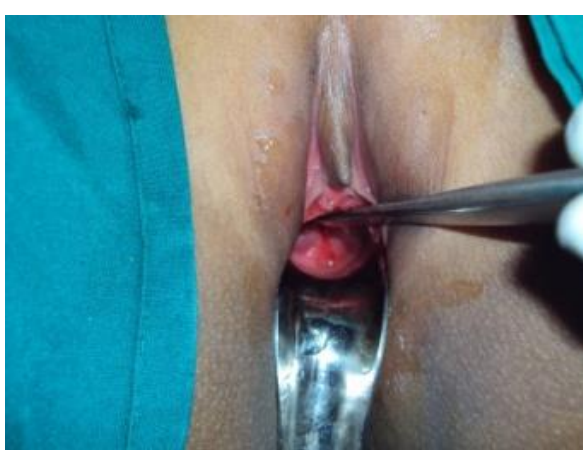

Figure 2: Per speculum examination showing hypoplastic cervix with pinpoint external os.
Per vagina

- Vaginal length $7.5 \mathrm{cms}$

- 2 fingers easy to pass into vagina

Per Rectal

- Knob like structure felt

Laparoscopy

- Fibrous band of uterine tissue seen

- Bilateral fallopian tubes seen

- Bilateral round ligaments seen

- Bilateral streak ovaries attached to ovarian ligament seen

- Bilateral uterosacral ligaments seen

- Pouch of Douglas normal

- All other intra-abdominal organs normal

- Biopsy from right streak ovarian tissue taken

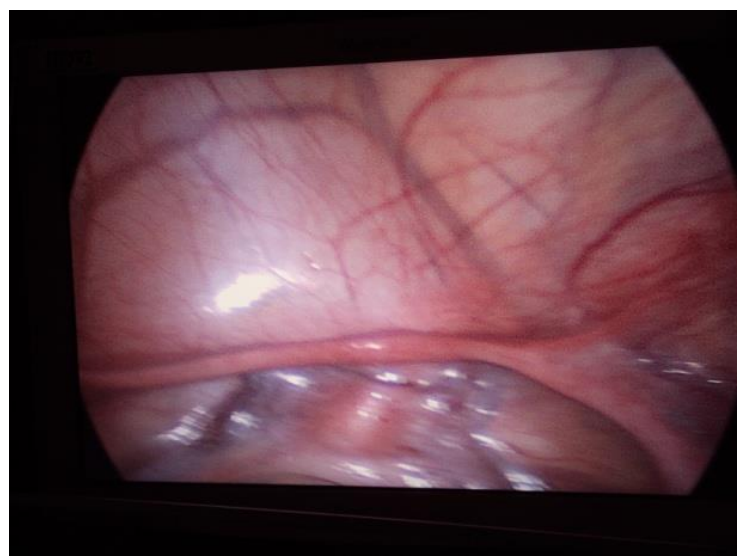

Figure 3: Laparoscopy showing fibrous band of uterine tissue, b/l fallopian tubes \& round ligament seen.

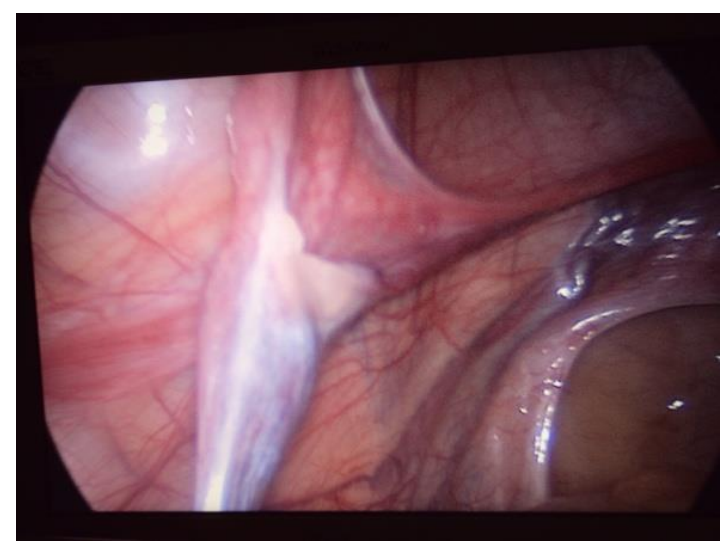

Figure 4: Laparoscopy showing streak ovaries karyotyping revealed $46 \mathrm{XY}$, autosomes normal, complete AIS. 

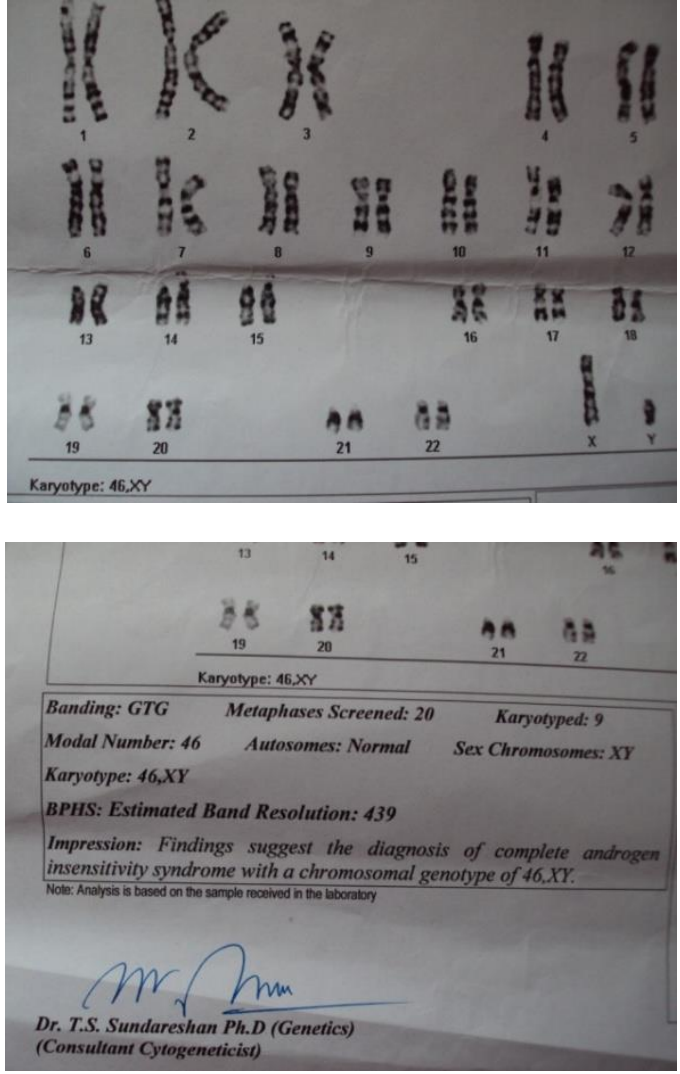

Figure 5: Chromosome analysis with GTG banding showed no structural or numerical abnormalities, the karyotype is $46, \mathrm{XY}$. Y fluorescence positive as detected by Q-banding technique.

The histopathology of the excised gonads showed ovarian stromal tissue. Subsequently the patient was started on hormone replacement therapy (HRT) with conjugated estrogens $0.625 \mathrm{mg}$ per day and cyclical medroxy progesterone acetate. Six months after initiation of HRT patient had one episode of spotting per vaginum. The secondary sexual characteristics have shown only a marginal improvement.

\section{DISCUSSION}

In utero, sexual differentiation follows a sequential pattern. After fertilization there is establishment of the genotype of the embryo and under the influence of the single gene determinant (testes determining factor) on the short arm of the Y chromosome, there is differentiation of the primordial gonads into the testes. The ovaries develop by default, in the absence or non functioning of the $\mathrm{Y}$ chromosome. This differentiation of the primordial gonads into the testes or ovary will lead to an alteration of the hormonal milieu of the fetus, which in turn results in the corresponding differentiation of the internal and external genitalia. We made a diagnosis of Swyer's syndrome because we had a normal statured girl with primary amenorrhoea, with clinical features of sexual infantilism, whose genotype was pure $\mathrm{XY}$ and the gonadal tissue showed features of ovarian stromal tissue. ${ }^{1}$

In Swyer's syndrome there is a mutation either in theYP11 location of SRY (sex determining region of Y chromosome $)^{2}$ or in other genes such as SOX9, DAX1, WTl or SF1 which can affect testicular differentiation and also inhibit anti mullerian hormone production. ${ }^{3}$ The main differential diagnosis of Swyer's syndrome is mixed gonadal dysgenesis which is more frequently seen than the former. In this condition the gonads on histopathology will also show testicular differentiation in addition to ovarian differentiation. The genotype too is usually a mosaic pattern. The incidence of malignant gonadoblastoma in patients with dysgenetic gonads is high $(25 \%)^{4}$ and hence bilateral gonadectomy has to be done.

These patients have a normal life expectancy provided they have undergone bilateral gonadectomy. These patients can have normal sexual relations and theoretically they can conceive using donor oocytes and Artificial Reproductive Techniques. They need to be on lifelong HRT, though it has been observed that inspite of incremental doses of estrogen therapy, development of breast and secondary sexual characteristics tends to be poor.

\section{REFERENCES}

1. Berek JS. Novak's Gynaecology, 12th ed. Philadelphia: Williams\& Wilkins 1996;786-7.

2. Hawkins JR. Mutational analysis of SRY in XY females. Human Mutations 1993;2:347-50.

3. Cotinot C, Pailhoux E, Jaubert F, et al. Molecular genetics of sex determination. Semin Reprod Med 2002; 20:157-67.

4. Speroff L, Glass RH, Kase NG. Clinical Gynecological Endocrinology and Infertility. 6th ed. Baltimore: Lippincott Williams and Wilkins 1999; 367-8.

5. Michala L, Goswami D, Creighton SM, Conway GS. Swyer syndrome: presentation and outcomes. BJOG. 2008 May;115(6):737-41.

DOI: $10.5455 / 2320-1770 . i j r \operatorname{cog} 20131248$

Cite this article as: Kusuma Naik MV, Nusrat AH,

Krishna L, Patil A, Pallavi. Swyer's syndrome: a rare cause of primary amenorrhoea. Int J Reprod Contracept Obstet Gynecol 2013;2:711-3. 